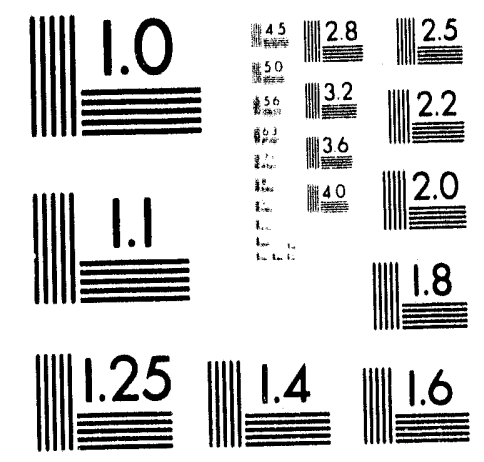



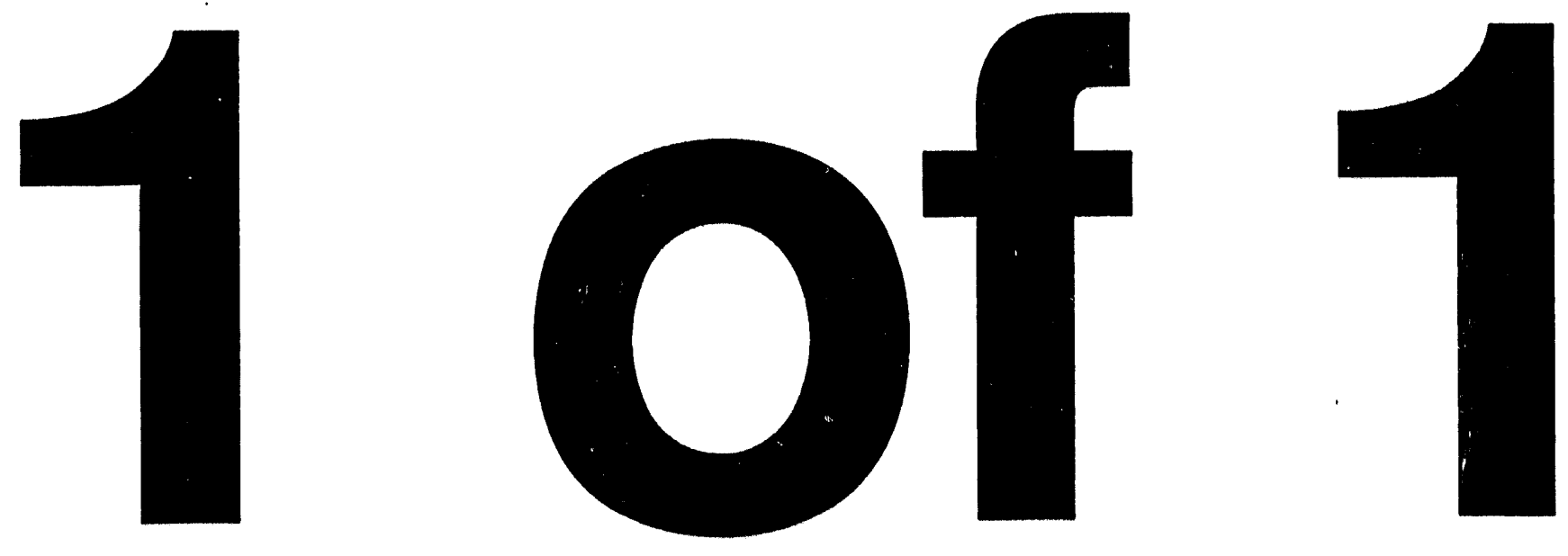


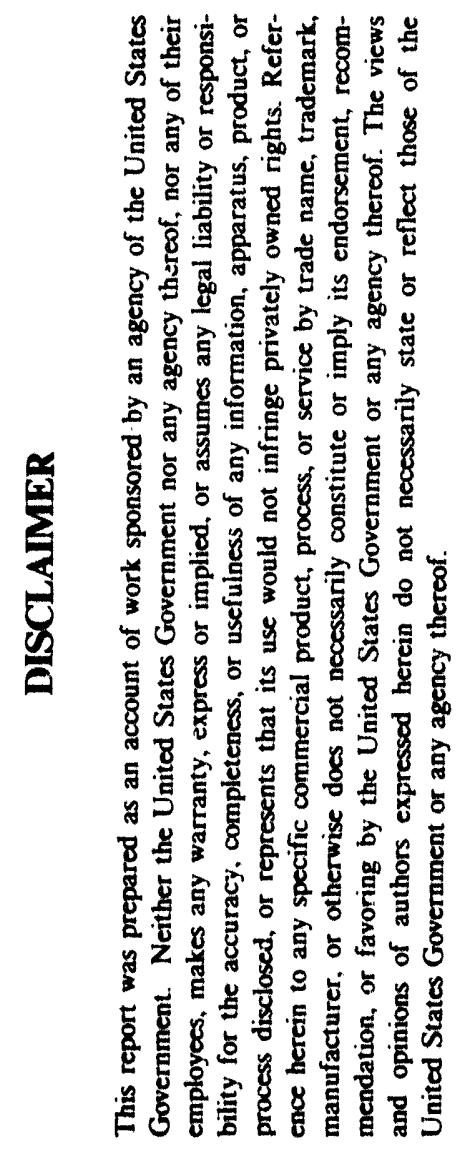

\section{Title: VARIABLE-FIELD PERMANENT MAGNET QUADRUPOLE FOR THE SSC}

David B. Barlow

Robert H. Kraus, Jr.

Ross E. Meyer

Ricardo P. Martinez

13th International Conference on Magnet Technology

Victoria Conference Centre

Victoria, B.C.

Canada

September 20-24, 1993

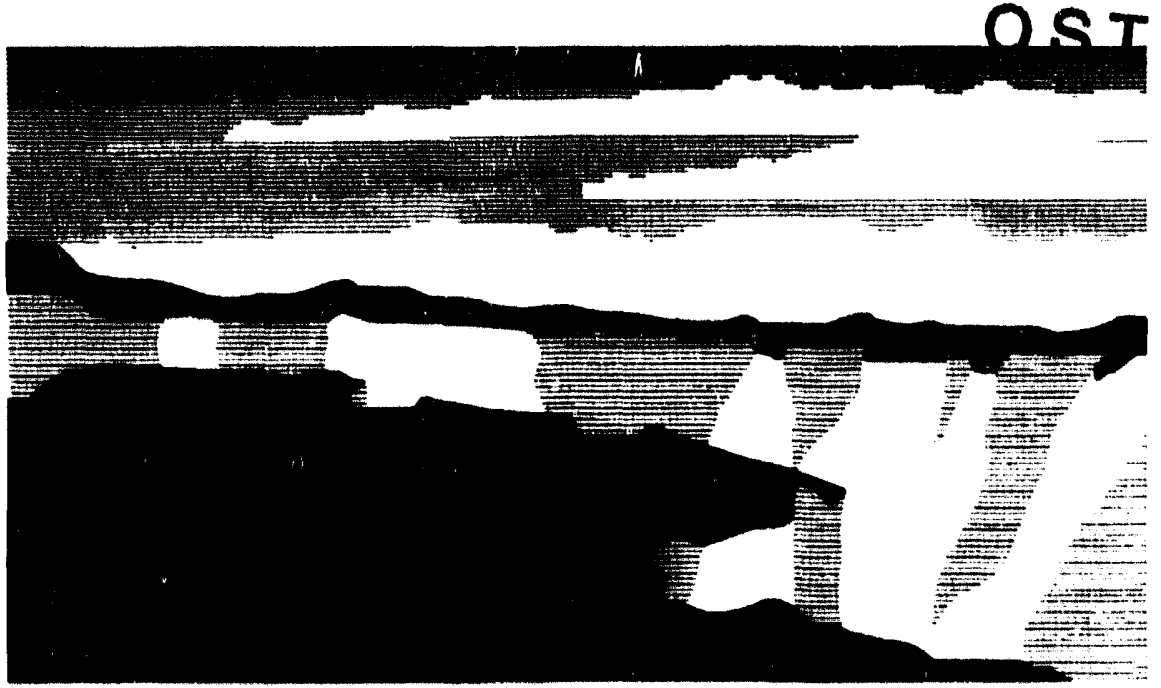

NATIONAL L.ABORATORY

Los Alamos National Laboratory, an affirmative actionequal opportunity employer, is operated by the Unlverstly of Calfornia lor the U.S. Department of t. nergy under contrac W-7405-ENG-36. By acceptance of this article, the publlsher recognizes that ine U.S. Government retains a nonexclusive, royalty.treu ilicense to publlsh or reproduce the published form of this contribution, or to allow others to do so, for U.S. Government purposes. The Los Alamos National l.aboratory requests that the publlsher identify this article as work pertormed under the auspices of the U.S. Department of Energy. 


\title{
Variable-Field Permanent-Magnet Quadrupole for the SSC*
}

\author{
David B. Barlow, Robert H. Kraus Jr., Ricardo P. Martinez, Ross E. Meyer, \\ Los Alamos National Laboratory \\ Los Alamos, NM 87545
}

\begin{abstract}
A set of compact varlable-fleld permanent-magnet quadrupoles have been designed, fabricated, and tested for use in the SSC ilnac matching section. The quadrupoles have $24 \mathrm{~mm}$ -dlameter apertures and $40 \mathrm{~mm}-10 n g$ poles. The hybrid (permanent-magnet and Iron) design, uses fixed core of magnet materlal (NdFeB) and Iron (C-1006) surrounded by a rotating ring of the same magnet material and Iron. The quadrupole gradient. length product can be smoothiy varied from a minimum of 0.7 ' $T$ up to a maximum, of $4.3 \mathrm{~T}$ by a $90^{\circ}$ rotation of the outer ring of Iron and magnet material.
\end{abstract}

\section{INTRODUCTION}

A set of compact variable-field permanent-magnet quadrupoles (VFPMQ) have been designed, fabricated and tested for use in the SSC linac matching section[1]. The magnetic design of the VFPMQ, shown in Fig. 1, is patterned after the conceptual design by $\mathrm{K}$. Halbach[2]. In brief, the bulk of the field is produced, and shaped by, a fixed core containing four iron poles separated by magnet material. The core is surrounded by an outer ring of magnet material and iron which can be rotated $90^{\circ}$ to vary the field from one extreme to the other. The magnets have a $24 \mathrm{~mm}$-diameter aperture, $40 \mathrm{~mm}$-long poles, and a gradient-length product (GL) that can be continuously varied from $0.7 \mathrm{~T}$ to $4.3 \mathrm{~T}$.

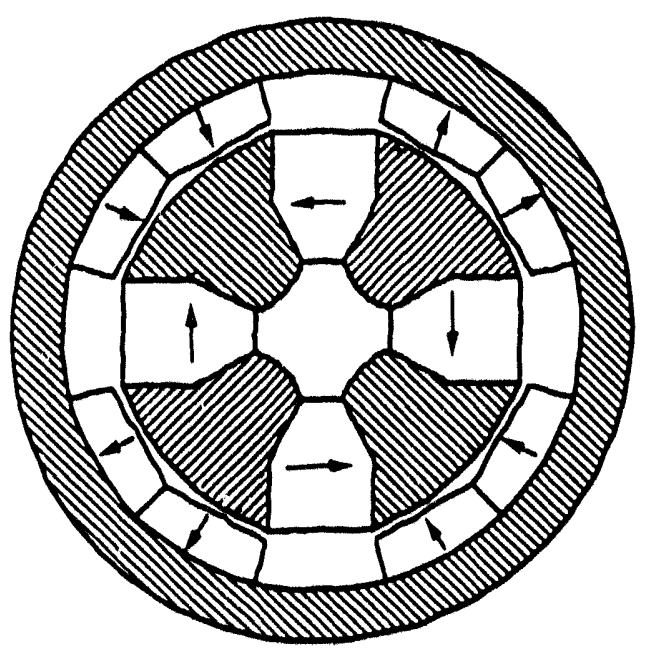

Fig. 1 Cross section of the magnetic components. The iron is indicated by the shaded areas, and the magnet material and orientation for maximum field are indicated by arrows.

* Manuscript received September 22, 1993. This work supported and funded by the US Department of Energy.

\section{MAGNETIC DESIGN}

The parameters specified for the magnet are listed in Table I. Also included in Table $I$ are the designed and measured parameters for the magnets. In order to keep the outside dimensions of the completed assembly as small as possible, $\mathrm{NdFeB}$ magnet material with a $\mathrm{B}_{\mathrm{r}}$ of $1.24 \mathrm{~T}$ was used for the design rather than the preferred SmCo magnet material which has a maximum $\mathrm{B}_{\mathrm{r}}$ of only $1.05 \mathrm{~T}$. The drawbacks of using $\mathrm{NdFeB}$ are that its magnetic temperature coefficient, $\Delta \mathrm{B} / \Delta \mathrm{T}$, is at least 3 times that of $\mathrm{SmCo}(0.1 \% / \mathrm{K}$ vs $0.03 \% / \mathrm{K}$ ), and that it is less resistant to radiation damage then the typical SmCo. The detailed magnetic-design work was done in two-dimensions using the FLUX2D[3] magnetic design code. It was assumed that the gradient-Iength product equals the gradient calculated in two-dimensions times the pole tip length. This assumption is true for magnets made entirely of $\mu=1$ magnet material, and has been found to be good to within a few percent for hybrid magnets. The dimensions of the magnet were optimized to produce the required gradient range with the minimum outside dimensions. Hyperbolic pole tips were used in the design to help reduce the higher order harmonic content. The shape of the hyperbolic pole tip was modified slightly to minimize the first allowed, $n=6$, harmonic. Further studies were conducted to evaluate the impact of fabrication and assembly errors as well as the effect that differences in the magnitude and orientation of the magnetic field in the magnetic blocks have on the field quality. The predictions of the final design were double checked using the three-dimensional TOSCA[4] magnet design code.

TABLE I

SPECIFIED, DESIGNED, AND MEASURED PARAMETtiRS

\begin{tabular}{|c|c|c|c|}
\hline Parameter & Specified & Designed & Measured \\
\hline $\begin{array}{l}\text { GL. min } \\
\text { GL. max } \\
n=3 \text { Hamonic }{ }^{\dagger} \\
n>4 \text { Harmonics }\end{array}$ & $\begin{array}{r}2.0 \mathrm{~T} \\
4.0 \mathrm{~T} \\
<1.0 \% \\
<0.5 \%\end{array}$ & $\begin{array}{r}0.9 \mathrm{~T} \\
4.4 \mathrm{~T} \\
<1.0 \% \\
<0.5 \%\end{array}$ & $\begin{aligned} & 0.7 \mathrm{~T} \\
& 4.3 \mathrm{~T} \\
&< 0.5 \% \\
&< 0.5 \%\end{aligned}$ \\
\hline
\end{tabular}

\section{MECHANICAL DESIGN}

A schematic of the mechanical assembly is shown in Fig. 2. The mechanical design is similar to previous VFPMQ's that have been designed and built by Los Alamos [5], [6] with the exception that there is only a single outer ring of magnet material and iron rather than two counter -rotating rings. This feature reduces the complexity of the mechanical design and drive system. The magnet is designed to fit in the short space between beam line components in the 
SSC linac's matching section, hence the short $46 \mathrm{~mm}$ overall length of the assembly, and the long arm to support the motor in a location where more space is available. The outer ring is rotated by a worm drive powered by a stepper motor. The stepper motor was sized to provide sufficient torque to overcome the outer ring's peak torque of $55 \mathrm{~N}$-m through the 100:1 gear reduction of the worm drive. The worm drive system has the additional advantage that it is does not allow the torque of the outer ring to be transferred back through the drive system. A pair of microswitches are used to limit the range of travel to $90^{\circ}$. At a nominal operating speed of 0.5 rps the motor can rotate the outer ring from one limit to the other in less than a minute. An incremental encoder is attached to the motor to provide relative-position read-out of the outer ring with respect to the reference position defined by the low-field limit switch. In addition a variable resistor was used to determine the absolute position of the outer ring. An clectric brake is provided to lock the position once the quadrupole has been set to the desired field. The orientation of the core of the magnet can be rotated a few degrees either way with respect to the housing by a pair of adjustment screws. This provides a convenient way to align the orientation of the quadrupole field with respect to fiducials on the exterior of the assembly. Not shown in Fig. 2 is the motor-driven translation stage that can move the entire assembly $\pm 2 \mathrm{~mm}$ in either the vertical or horizontal direction. This feature allows the quadrupoles to steer as well as focus the beam.

\section{TEST AND MEASUREMENT}

Before the VFPMQ's were assembled the magnitude and orientation of the segments of magnet material were measured using a rotating-sample magnetic-moment mapper similar to the device described in [7]. Segments that exceeded the specified tolerance were rejected, and the remaining segments were sorted into sets of comparable strength. Since the profile of the iron pole pieces is also critical to the field quality they were inspected to insure that they were within the specified tolerance. After the assembly and mechanical checkout were complete, detailed measure-ments were made of one of the magnets to characterize the magnetic performance. A rotatingcoil was used to measure the gradient-length product (GL) as a function of the orientation of the outer ring, Fig. 3. Also shown in Fig. 3 are the GL's calculated from the twodimensional model. The differences between the calculations and the measured results is believed to be due to differences between the simplified two-dimensional model and actual mechanical design. The rotating-coil measurements showed no indication of any hysterisis effects or mechanical backlash. The setting of the quadrupole field was repeatable to better than $0.001 \mathrm{~T}$. The rotating-coil was also used to determine the harmonic content and phase angle of the integral

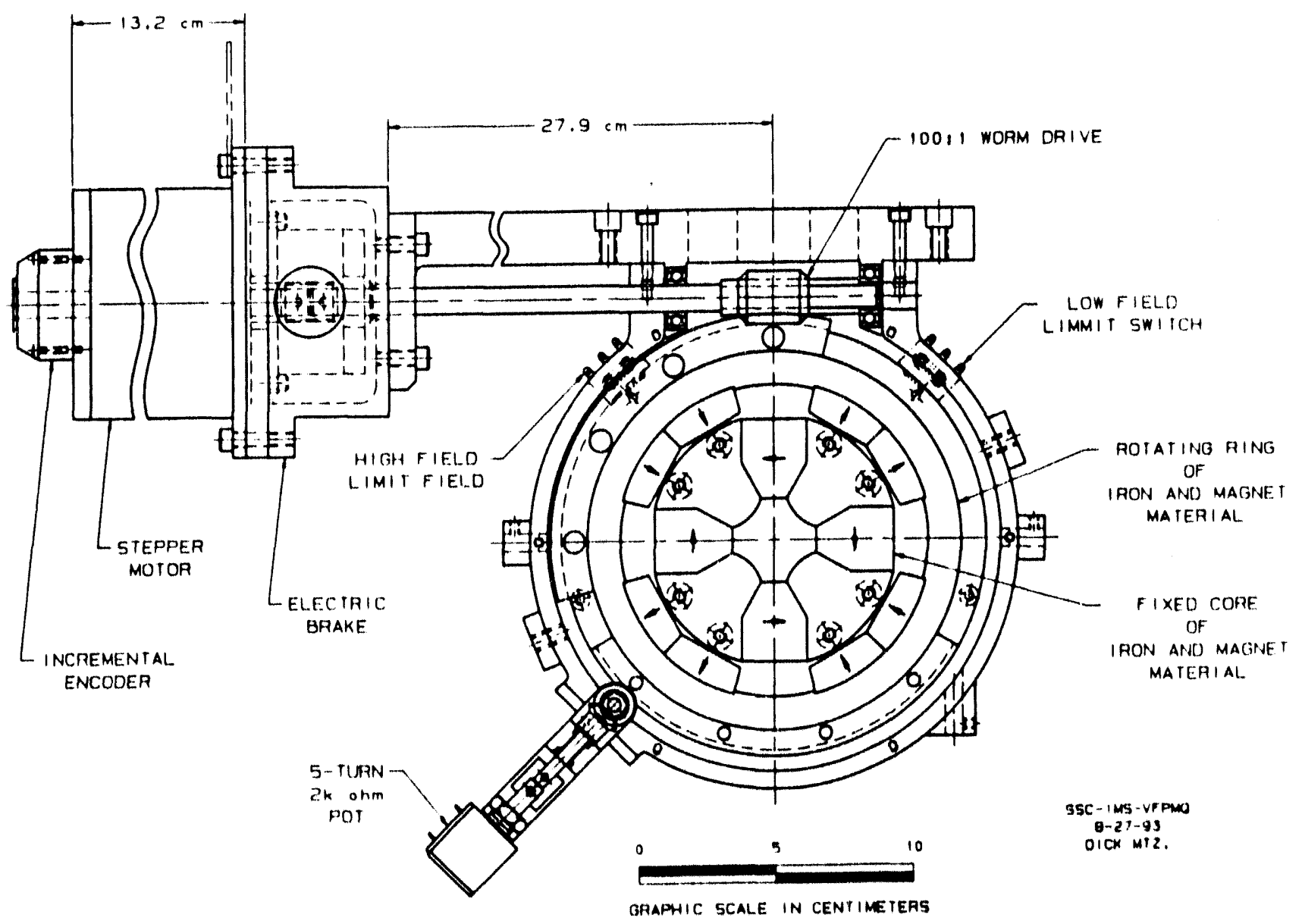

Fig. 2 Schematic end view of the mechanical assembly. 
aquadrupole field as a function of the GL. The measured harmonics, shown in Fig. 4, were found to be well within specification over the nominal operating range of the magnet. The change in the orientation of the quadrupole field (phase angle) as a function of the magnitude of the quadrupole field (GL) is shown in Fig. 5. As expected the phase angle has a systematic shift due to the fringe field of the single outer ring of iron and magnet material. Next a small Hall probe was used to point map the radial ficld distribution along the magnetic axis at several different radii, for the magnet set at its maximum field position. The measured distributions are shown in Fig. 6 along with the distributions calculated by TOSCA at the same radii and field setting. The slope in the measured data near $\mathrm{z}=0$ is due to small, $\sim 6 \mathrm{mr}$, misalignment of the Hall probe's axis of travel with respect to the magnetic axis. The two peaks in the distribution at the largest radius

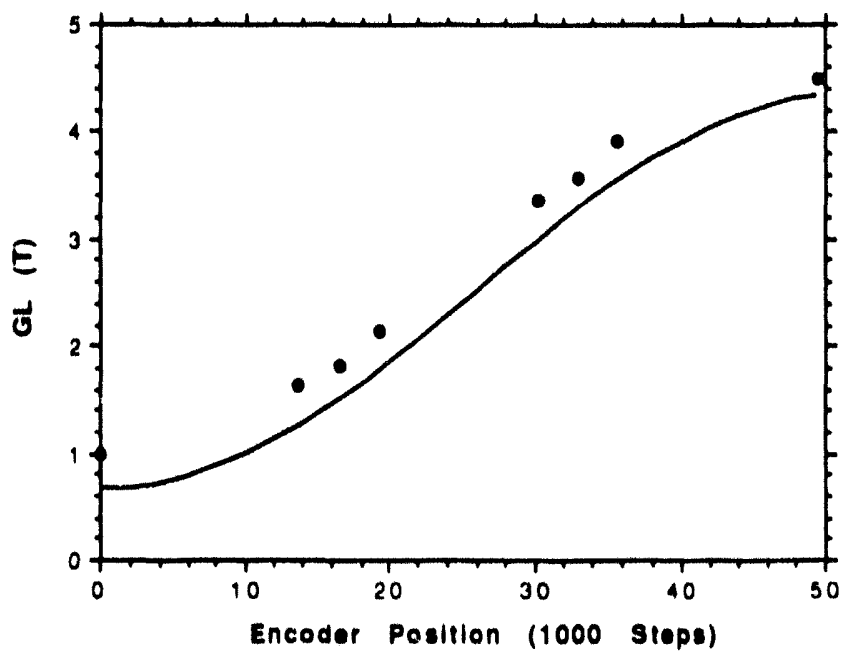

Fig. $3 \mathrm{GL}$ vs encoder step count measured with the rotatingcoil (smooth curve) and calculated (dots).

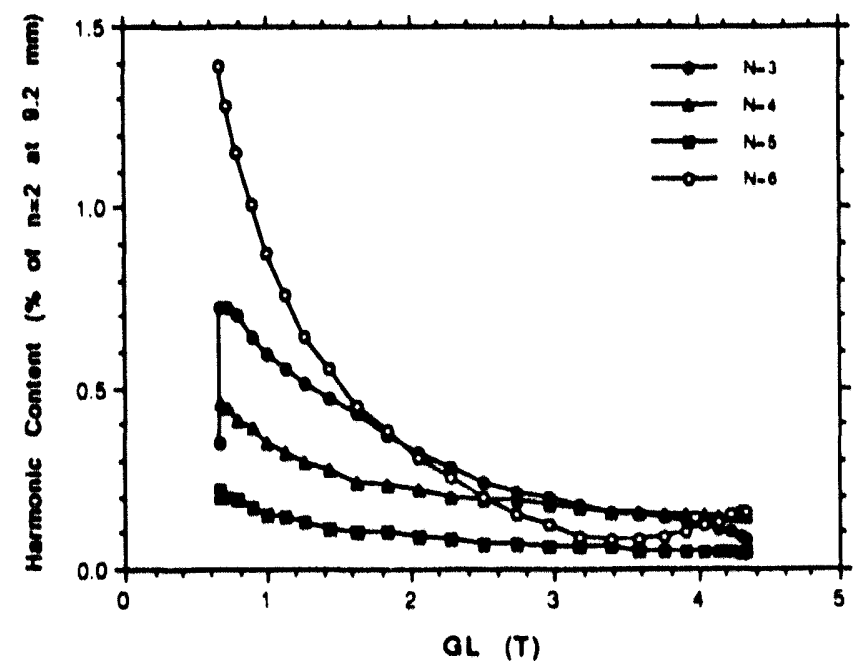

Fig. 4 Harmonic content vs GL measured by the rotating-coil at a radius of $9.2 \mathrm{~mm}$. are due to the field concentration at the sharp edges at the ends of the pole tips. The effective length of the ficld distribution, defined as the full width at half maximum, were found to have a slight radial dependence that was extrapolated to a length of $48.9 \mathrm{~mm}$ on the axis.

\section{CONCLUSION}

A compact high-field variable-field permanent-magnet quadrupole has been designed, fabricated, and tested. The gradient-length product of this magnet is much higher then anything available in a comparably sized electro magnet. The GL can be smoothly varied over a wide range, is extremely reproducible, and of high quality. VFPMQ's have proven to be reliable and are rapidly becoming essential accelerator components wherever beam line space is at a premium.

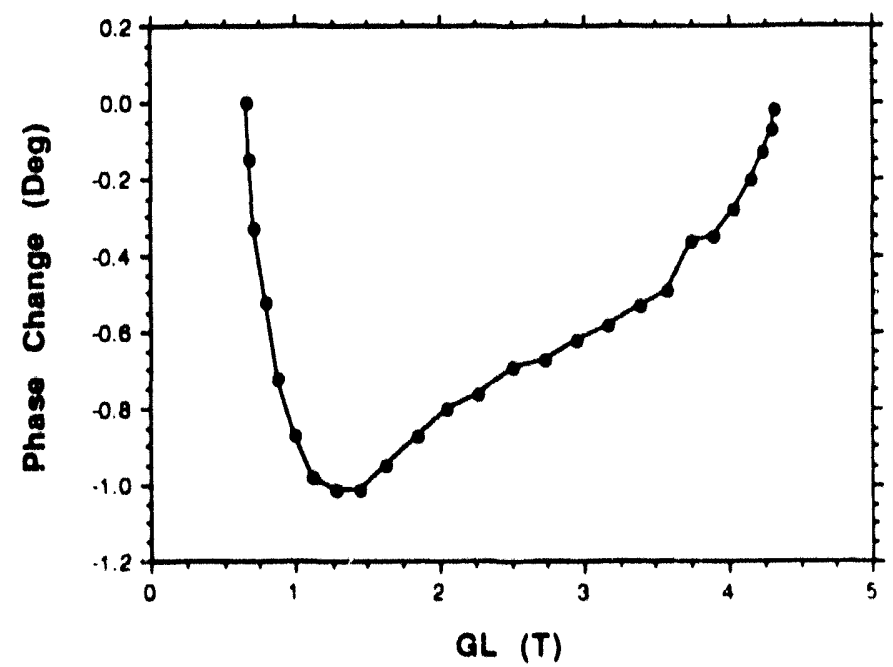

Fig. 5 Rotating-coil measurement of the change in orientation of the integral quadrupole ficld (phase) vs the magnitude (GL).

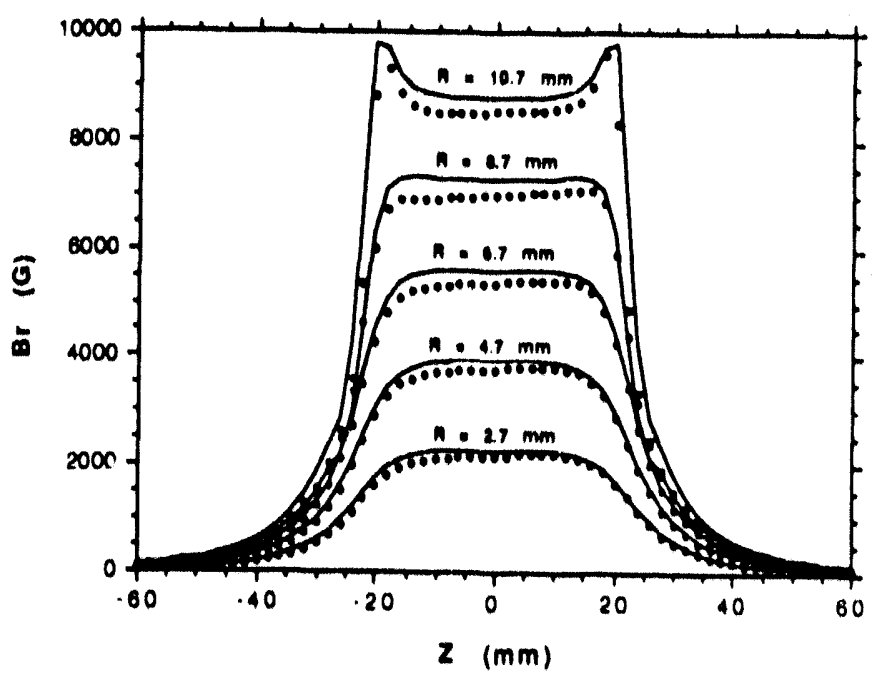

Fig. 6 Radial ficld distribution at several different radii measured (dots), and calculated in three-dimensions (smooth curves). The results are for maximum field. 


\section{REFERENCES}

[1] M. Haworth et al., "Finalized design of the SSC RFQDTL matching section," Proceedings of the 1993 Particle Accelerator Conference, in press (1993).

[2] K. Halbach, "Conceptual design of a permanent quadrupole magnet with adjustable strength," Nuclear Instruments and Methods 206, pp. 353-354 (1983).

[3] FLUX2D magnet design code, Magsoft Corp, Troy NY.

[4] TOSCA magnet design code, Vector Ficlds Inc, Aurora IL

[5] R. H. Kraus Jr., P. F. Ruminer, "IMS variable-field quadrupole measurements.", Los Alamos National Laboratory technical note AT-3:89-28, unpublished (1989).

[6] K. C. D. Chan et al., "Design of a compact applicationoriented free-electron laser," 1992 Linear Acceleralor Conference Proceedings, pp 37.39 (1992).

[7] D. H. Nelson, P. J. Barale, M. 1. Green, and D. A. VanDyke, "The Lawrence Berkelcy Laboratory magnetic. moment sorting system." Proceedings of the 9 th International Conference on Magnet Technology, pp. 735 -738 (1985). 

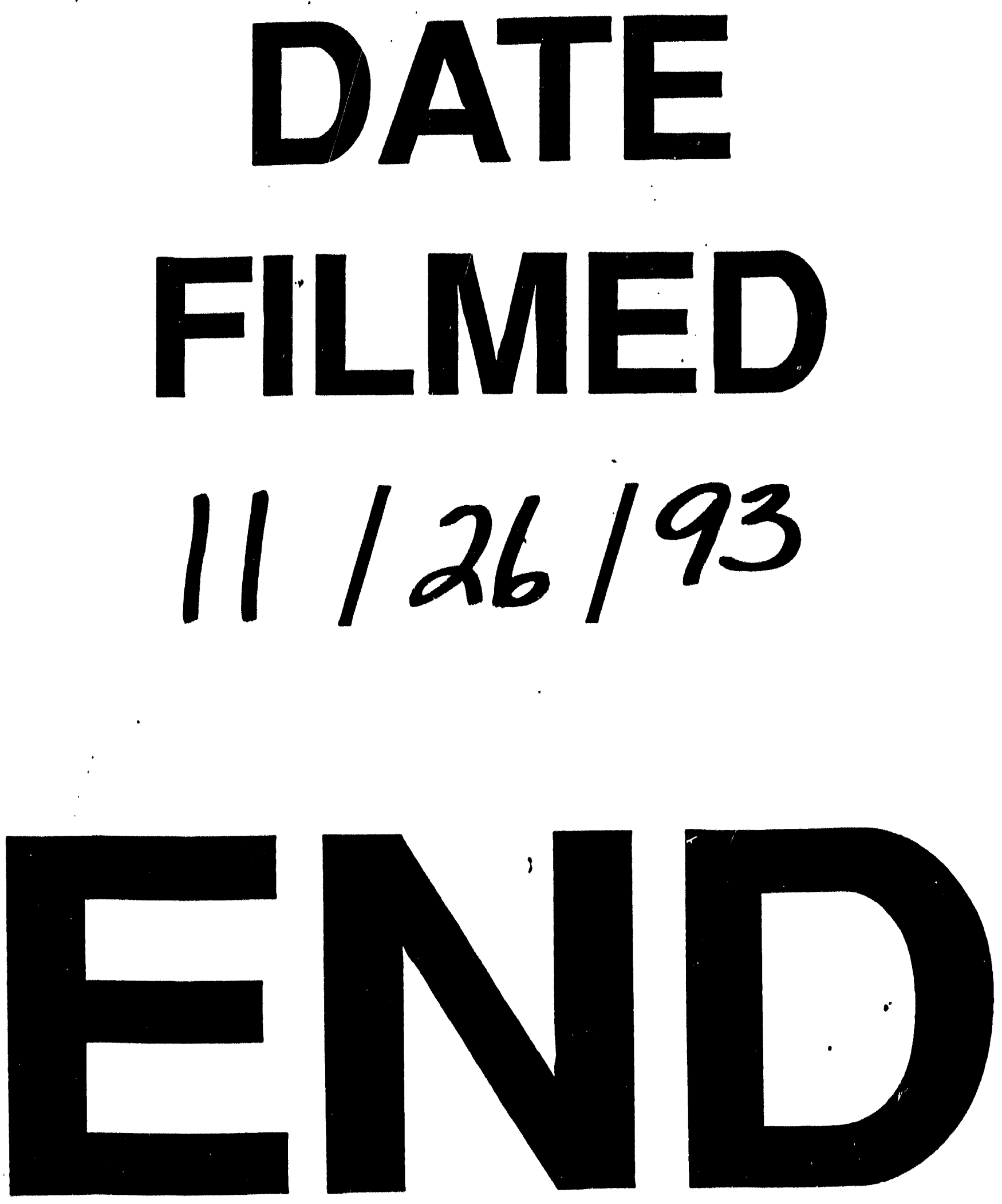
